\title{
The Study of Human Osteoblast-Like MG 63 Cells Proliferation on Resorbable Polymer-Based Nanocomposites Modified with Ceramic and Carbon Nanoparticles
}

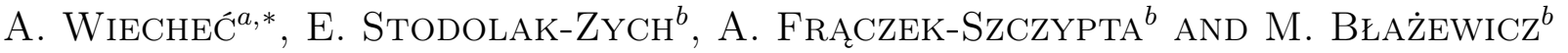 \\ AND W.M. KWIATEK ${ }^{a}$ \\ ${ }^{a}$ The Henryk Niewodniczański Institute of Nuclear Physics, Polish Academy of Sciences, Kraków, Poland \\ ${ }^{b}$ Faculty of Material Science and Ceramic, Department of Biomaterials, AGH-University of Science and Technology \\ Kraków, Poland
}

\begin{abstract}
Polymer-based nanocomposites containing biocompatible and bioactive nanocomponents seem to be excellent materials that could be used in many biomedical applications. The aim of this study was biological evaluation of resorbable polymer-based nanocomposites (PLA, PCL) and their modifications with ceramic nanoparticles (silica - $\mathrm{SiO}_{2}$, montmorylonit - MMT) or carbon nanotubes. The nanocomposites were seeded with the human osteoblast-like MG 63 cells. After 1, 3 and 7 days of incubation, Trypan blue exclusion test was used to determine the viability and number of cells. The cell population density depending on incubation time and cell population doubling time was calculated. The cell proliferation abilities on the all applied nanocomposites and on control material (polystyrene cell culture plate) were also compared. The number of cells growing on the nanocomposite surfaces increased with the incubation time. The cell viability was not decreased for all applied materials during the entire study (97-100\%). The ceramic nanoparticles and carbon nanotubes modified the bone cell growth and proliferation rate. Results of this study confirm that all types of the nanocomposites are appropriate to the growing and proliferation of human osteoblast-like cells.
\end{abstract}

PACS: $82.35 . \mathrm{Np}$, 87.17.Ee

\section{Introduction}

Polymer-based nanocomposites containing biocompatible and bioactive nanocomponents seem to be excellent materials that could be used in many biomedical applications. There is a new research direction for tissue engineering and bone regeneration [1].

Polymers such as copolymer L/DL lactide (PL/DLA) and polycaprolactone (PCL) are characterised by good biocompatibility and biodegradability That is why they have been extensively applied in surgical threads, implant materials, tissue engineering, and control drug delivery system. However, their modification with ceramic or carbon nanoparticles could change mechanical, electrical, physical and chemical properties of polymer matrix [2]. The nanofillers may influence the cellular response (such as adhesion and proliferation ability of cells) which is in charge of the good biocompatibility of the material and thus determines its applicability in medicine.

In this study nanofillers such as silica, montmorillonite and carbon nanotubes were used as modification of polylactide and polycaprolactone.

\footnotetext{
* corresponding author; e-mail: anna.wiechec@ifj.edu.pl
}

Silica $\left(\mathrm{SiO}_{2}\right)$ may interact with positive calcium ions, forming calcium compounds which combine with phosphate ions forming an amorphous calcium phosphate that finally crystalizes and forms structure similar to hydroxyapatite-like structure in bone. Silica $\left(\mathrm{SiO}_{2}\right)$ in solvent are characterized by different forms resulting from the chemical behaviour of $\mathrm{Si}$ atom. It shows tetrahedral coordination, with 4 oxygen atoms surrounding a central $\mathrm{Si}$ atom $\left(\left[\mathrm{SiO}_{4}\right]^{4-}\right)$. In water solution (i.e. in simulated body fluid - SBF) negative charge of silica attracts positive cation of calcium. This is reason why the $\mathrm{Ca}-$ $\left[\mathrm{SiO}_{4}\right]^{4-}$ formation is possible. Intermediate state was neither observed nor studied. Many authors reported that the silica-containing bioactive materials have the potential ability to activate bone-related gene expression and stimulate cell proliferation $[3,4]$.

Montmorillonite (MMT) is 2:1 phyllosilicate mineral which is well known in a drug delivery system, as a nanofiller in polymer-based nanocomposite or crystals. Modification of MMT clay (exfoliation or intercalation) strongly influence mechanical properties of nanocomposites materials. Durability of nanocomposites depends on amount and kind of nanofiller. These features allow to get optimal characteristics of different implants in bone 
surgery [5].

Carbon nanotubes (CNTs) are currently regarded as ideal materials both for technical and medical application. CNTs have proven to be highly biocompatible because of their mechanical and electrical properties. Then, CNTs behave like an inert matrix to support cell proliferation, their effect along with other natural or synthetic materials as biocomposites would be more effective in bone tissue engineering applications. Bone cell functions are stimulated under electrical current, and therefore conductive nanoadditives like carbon nanotubes may play a role in promoting osteoblast growth and proliferation [6].

The aim of this study was biological evaluation of resorbable polymer-based nanocomposites (PLA, PCL) and their modifications with ceramic nanoparticles $\left(\mathrm{SiO}_{2}, \mathrm{MMT}\right)$ or CNTs. The question was whether the nanocomposites might affect bone cell growth and proliferation rate and whether cellular response might be changed by nanofillers.

\section{Materials and methods}

\subsection{Resorbable polymer-based nanocomposites modified with ceramic and carbon nanoparticles}

The resorbable polymer-based nanocomposites PLA, PCL, and their modifications with ceramic nanoparticles or carbon nanotubes, were applied for biological evaluation. The PCL was modifed with $0 \%$ and $0.5 \%$ MMT. The polylactide (PLA) was modifed with $0 \%, 1 \%$ CNT (multi-walled carbon nano tubes) and $1 \%$ $\mathrm{SiO}_{2}$ (nanosilica provided by NanoAmor, USA). The preparation of nanocomposites and their physicochemical properties were described in [7]. Pure polymer samples: PLA and PCL were used as reference material.

Static mechanical properties of the nanocomposites (tensile strength, $R_{\mathrm{M}}$ ) were determined in the tensile mode using an universal testing machine Zwick testing machine model 1435 with the crosshead speed of 2 $\mathrm{mm} / \mathrm{min}$. According to the definition: "tensile strength $\left(R_{\mathrm{M}}\right)$ is the maximum stress that a material can withstand while being stretched or pulled before necking, which is when the specimen's cross-section starts to significantly contract" [8]. Surface properties such as wettability and topography were determined by measurement contact angle method (Kruss 10 DSA) and nanoroughness (average of roughness, $R_{\mathrm{a}}$ ) observed using atomic force microscope, AFM (Explorer, Veeco, USA) and profilometry (Hommel Tester TK300).

\subsection{Cell culture on the nanocomposites}

All materials were seeded with human osteoblast-like MG 63 cells (European Collection of Cell Cultures, Salisbury, UK) in densities $\approx 20,000$ cells $/ \mathrm{cm}^{2}$ and incubated for 1 to 7 days in minimum essential medium supplemented with $10 \%$ fetal bovine serum and $1 \%$ penicillin - streptomycin, $0.1 \%$ non essential amino acids and $0.1 \%$ sodium pyruvate (all compounds from Immuniq) at $37^{\circ} \mathrm{C}$ in a humidified air atmosphere containing $5 \% \mathrm{CO}_{2}$. The morphology was evaluated in cells fixed with cold $70 \%$ ethanol $\left(-20^{\circ} \mathrm{C}, 5 \mathrm{~min}\right)$ and stained with propidium iodide (PI, $5 \mathrm{mg} / \mathrm{ml}, 5 \mathrm{~min}$ ). In the $1 \mathrm{st}, 3 \mathrm{rd}$, and 7th day after seeding, the viability and number of cells were examined. The cells were detached with a $0.05 \%$ trypsin-EDTA solution (Immuniq) in phosphate buffered saline (PBS) for $8 \mathrm{~min}$ at $37^{\circ} \mathrm{C}$, resuspended in the cell culture medium and analyzed by Trypan blue exclusion test. The principle of Trypan blue test is based on the fact that alive cells possess intact cell membranes that exclude Trypan blue dye, whereas dead cells do not. The cell numbers were expressed as cell population densities per $\mathrm{cm}^{2}$. The cell population doubling time (DT) was calculated as DT $=\left(t-t_{0}\right) \log 2 /\left(\log N t-\log N t_{0}\right)$, where $t_{0}$ and $t$ represent earlier (1st day) and later (3rd day) time intervals after seeding, respectively, and $N t_{0}$ and $N t$ - the number of cells at these intervals. As a control material in biological study polystyrene (PS) cell culture plate (Sarstedt, Germany) was used.

\subsection{Statistics}

The results were expressed as means \pm SEM obtained from 3-4 samples for each experimental group. For cell population doubling time, the errors were calculated by exact differential method. The one way analysis of variance (ANOVA) was performed. The $p$ values equal to or less than 0.05 were considered significant.

\section{Results and discussion}

\subsection{Introduction of nanofillers in polymer matrix influences mechanical properties of materials}

The better mechanical properties of nanocomposites were confirmed by high level of nanofillers dispersion and by interaction between nanofiller and polymer matrix. Tensile strength was increased in all kinds of samples after $1 \mathrm{wt} \%$ nanofillers modification (Table I). These results verify homogeneous distribution of nanofillers, and confirm effective methods to obtain nanocomposites materials. The significant experimental data characteristic for polymer-based nanocomposites were presented in Table I.

Only small percentage of nanofillers (such as $1 \%$ CNT and $0.5 \% \mathrm{MMT}$ ) in nanocomposites influences physicochemical properties of nanocomposite. Contact angle increased in nanocomposite samples (PLA/CNT, PCL/ $\mathrm{MMT})$ compared to the pure polymer $\left(\approx 75.5^{\circ}\right.$ for $\mathrm{PLA}$ and $\approx 78.8^{\circ}$ for PCL). Nanosilica (such as MMT) decreased hydrophobicity of nanocomposite surface in comparison to others (Table I). This effect is result of interaction between active chemical group exposed on silica surface and polymer chain in PLA $/ \mathrm{SiO}_{2}$ nanocomposite. Presence of ceramic nanofillers in polymer matrix changes nanotopography of surface. Consequence of the presence of active $\mathrm{SiO}_{4}^{4-}$ groups on the silica nanoparticle surface is the change of the average surface roughness 
and creation of domains which can modify the material texture. In this study the higher roughness is characterized also for nanocomposites in comparison to polymer matrix. It seems that all applied nanocomposites can be more suitable for adhesion and spread of cells in comparison to polymer matrix. Literature date showed that texture factor (roughness and elasticity of surface) can be determined to adhering and proliferation of osteoblastic cells [9]. That is consistent with our findings. The comparison of physicochemical properties with biological results indicates that applied nanocomposites are more suitable for osteoblasts growth than polymer matrix (details below).

TABLE I

Physicochemical properties of nanocomposites materials based on PLA and PCL: tensile strength $\left(R_{\mathrm{M}}\right)$, wettability (contact angle) and roughness (profilometry $[\mu \mathrm{m}]$ and AFM $[\mathrm{nm}]$ measurements).

\begin{tabular}{l|c|c|c|c}
\hline \hline \multicolumn{1}{c|}{ Materials } & $\begin{array}{c}R_{\mathrm{M}} \\
{[\mathrm{MPa}]}\end{array}$ & $\begin{array}{c}\text { Contact angle } \\
\theta\left[{ }^{\circ}\right]\end{array}$ & $\begin{array}{c}\text { Profilometry } \\
R_{\mathrm{a}}[\mu \mathrm{m}]\end{array}$ & $\begin{array}{c}R_{\mathrm{a}} \text { AFM } \\
{[\mathrm{nm}]}\end{array}$ \\
\hline $\mathrm{PCL}$ & $11.3 \pm 2.1$ & $78.8 \pm 3.65$ & 0.52 & 67.28 \\
$\mathrm{PCL} / 0.5 \% \mathrm{MMT}$ & $18.6 \pm 3.5$ & $79.5 \pm 2.95$ & 0.81 & 132.25 \\
$\mathrm{PLA}$ & $26.1 \pm 2.6$ & $75.5 \pm 3.23$ & 0.36 & 15.8 \\
$\mathrm{PLA} / 1 \% \mathrm{CNT}$ & $40.3 \pm 6.8$ & $77.2 \pm 1.47$ & 0.19 & 199.56 \\
$\mathrm{PLA} / 1 \% \mathrm{SiO}_{2}$ & $37.3 \pm 3.8$ & $73.6 \pm 2.25$ & 0.29 & 115.57
\end{tabular}

\subsection{Human osteoblast-like MG 63 cells proliferation on nanocomposites}

The cell viability, estimated on the based of Trypan blue exclusion test, was not decreased for all applied nanocomposites. The measurement was done in 1st, 3rd and 7th day after seeding. During the entire study, the cell viability was $97-100 \%$. Such high cellular survival means that the applied nanocomposites as well as polymer matrix do not exhibit cytotoxic properties. However it is suggested [10] that for certainty, non-cytotoxic property should be additionally confirmed in other tests. In this case the colorimetric assays measuring the enzyme activity that are normally inside cells might be applied. For example the cellular redox activity of succinate dehydrogenase might be evaluated by the tetrazolium salt reduction (express as colored end products) in tests: MTT (3-(4,5-dimethylthiazol-2-yl)-2,5-diphenyltetrazolium bromide, a yellow tetrazole reduced to purple formazan in living cells) or XTT (2,3-bis-(2-methoxy-4-nitro-5-sulfophenyl)-2H-tetrazolium-5-carboxanilide - more sensitive, the formed formazan dye is water soluble, which allows avoiding a final solubilization step). These tests are recommended for measurement of cytotoxicity and proliferation ability [10].

Figure 1 shows the results of comparison of the number of cells growing on the nanocomposites with the number of cells in the control material (dedicated to the conducting cell cultures). The difference between the population density was counted according to the formula: "cell number on the nanocomposites minus cell number on the control material". Thus, the value zero is equal to the number of control cells. For values below zero, the number of cells on the nanocomposites is lower than the number of control cells, whereas for values above zero, the number of cells is higher. The density of cell population determined on the nanocomposites was significantly lower in comparison to the control material (polystyrene cell culture plate) (Fig. $1 \mathrm{~A}-\mathrm{C}$ ). After 1st and 3rd day of incubation on the nanocomposites the differences between the number of cells counted on the control material and on nanocomposites were ranked in the range of mean \pm one standard deviation (Fig. 1A,B). The highest differences (range of mean \pm two standard deviations) were observed on 7th day of incubation for polycaprolactone and nanocomposites with ceramic nanofillers (Fig. 1C). The most similar number of cells counted on the nanocomposites (in comparison to control) was observed for $1 \%$ CNT on PLA. Particularly after 7 days of cell culturing the numbers of cells on the $1 \% \mathrm{CNT}$ on PLA were equal to control material (Fig. 1C, sample no. 2a). This finding confirms that nanocomposites with carbon nanotubes are appropriate to the growing and proliferation of human osteoblast-like cells.

Although the cell density on the nanocomposites was lower than on control material, the growing and proliferation of MG63 cells was observed on nanomaterials. Figure 2 presents the real number of cells counted on nanocomposites after 1st, 3rd and 7th days of culturing. The results gives us information what is the density of cell population on the surface of nanocomposites in each time intervals. The number of cells counted on the nanocomposite surfaces increased with the incubation time (Fig. 2). An exponential growth curve was 


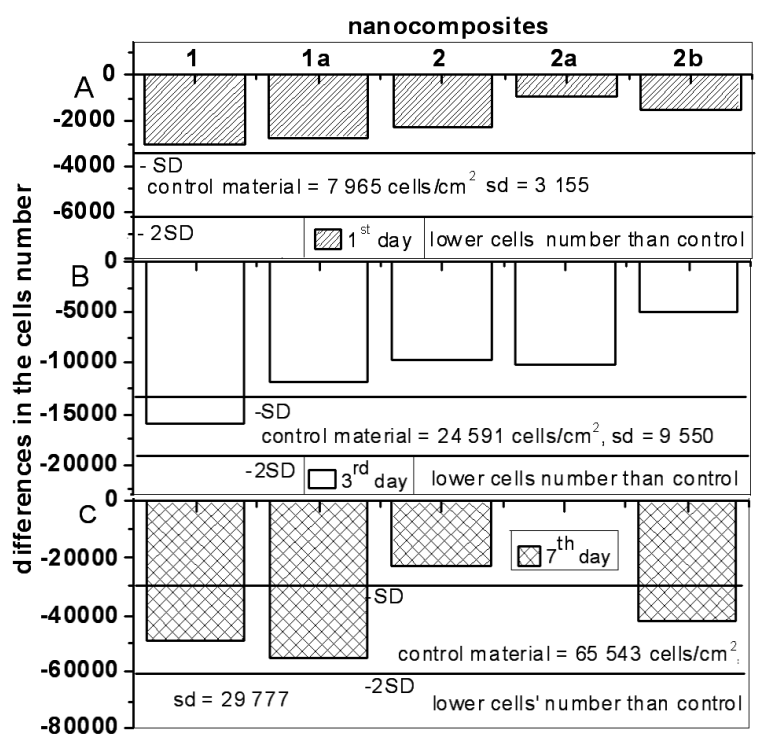

Fig. 1. Number of cells growing on the nanocomposites shown as differentiation with respect to the avarage number of cells on the PS (control material) (formula: cell number on the nanocomposites minus cell number on the control material) after 1st (A), 3rd (B) and 7th (C) day of culturing; 1 - PCL, 1a - PCL with $0.5 \% \mathrm{MMT}, 2-\mathrm{PLA}, 2 \mathrm{a}-\mathrm{PLA}$ with $1 \% \mathrm{CNT}, 2 \mathrm{~b}-$ PLA with $1 \% \mathrm{SiO}_{2}$.

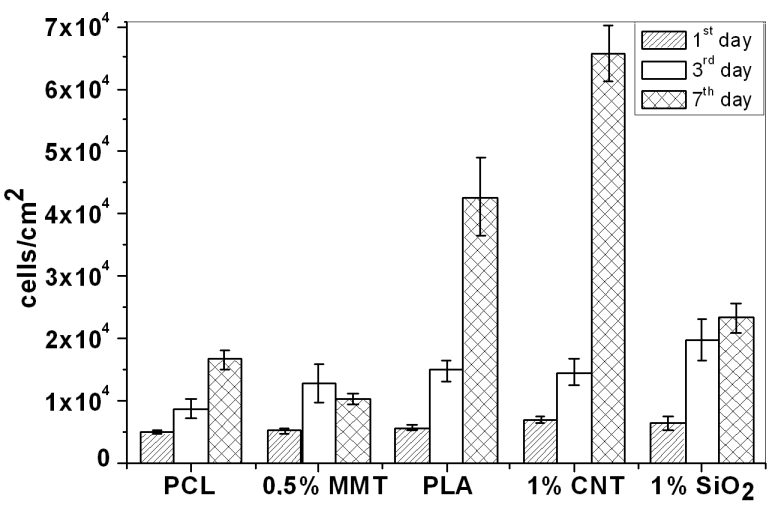

Fig. 2. The MG63 cells population density on PCL and PLA and their modifications.

observed for cells cultured on the nanocomposites surfaces. The 1st day after seeding higher number of MG63 cells was observed for modified polymers. The physicochemical properties, described above, caused the better adhesion and spread of cells. Moreover, cells growing on the CNT surface were characterized by the largest number of cells compared to all used nanocomposites after 7 days of incubation.

The cell population doubling time is dependent on the material on which the cells were seeded. The cell population doubling times estimated in this study are presented in Table II. The MG63 cells doubling time growing on the polystyrene was $29.5 \pm 3.7 \mathrm{~h}$, and it is similar to results obtained by others $[10,11]$. The cell population doubling time on the PCL was twice higher than the control (58.3 vs. $29.5 \mathrm{~h}$ ). However, the application of ceramic nanoparticles in polymer matrix reduced the time $(0.5 \% \mathrm{MMT}=37.4 \mathrm{~h})$. On the PLA, the cell population doubling time $(37.6 \mathrm{~h})$ was 1.3 times higher than on control material. The presence of ceramic nanoparticles in PLA matrix also resulted in reduction of the cell population doubling time $\left(1 \% \mathrm{SiO}_{2}=29.6 \mathrm{~h}\right)$. The carbon nanoparticles in PLA matrices slightly increased the cell population doubling time $(46.1 \mathrm{~h})$.

TABLE II

The cell population doubling time on the control material and nanocomposites. Formula: DT $=(t-t) \log 2 / \log N_{t}-$ $\log N_{t 0}$, where $t_{0}, t$ - earlier (1st day) and later (3rd day) time intervals after seeding, $N_{t 0}, N_{t}$ - the number of cells at these intervals; error by exact differential method was made.

\begin{tabular}{c|c|c|c|c}
\hline \hline No & Material & Modification & $\begin{array}{c}\text { Doubling time } \\
{[\mathrm{h}]}\end{array}$ & $\begin{array}{c}\text { Error } \\
{[\mathrm{r}]}\end{array}$ \\
\hline 1 & $\begin{array}{c}\text { polystyrene } \\
\text { (control) }\end{array}$ & none & 29.5 & 3.7 \\
\hline 2 & PCL & none & 58.3 & 5.2 \\
3 & & $0.5 \% \mathrm{MMT}$ & 37.4 & 4.1 \\
\hline 4 & \multirow{2}{*}{ PLA } & none & 37.6 & 4.0 \\
5 & & $1 \% \mathrm{CNT}$ & 46.1 & 4.6 \\
6 & & $1 \% \mathrm{SiO}_{2}$ & 29.6 & 3.7
\end{tabular}

The celular proliferation strongly depends on surface properties such as wettability, surface energy and roughness. The surface roughness in micro- and nanoscale is particularly important for bone cells. The presences of nanoparticles in polymer matrix change significantly the nanoroughness of nanocomposites in comparison with pure polymer. For ceramic nanoparticles $\left(\mathrm{MMT}, \mathrm{SiO}_{2}\right)$ the nanoroughness is within $100 \mathrm{~nm}$ which is optimal level for stimulation of cells to proliferation according to [12]. In this study the value of the cell population doubling time is the most favourable for samples with MMT, $\mathrm{SiO}_{2}$ and CNT which may confirm that the roughness has a decisive influence on the cells behavior. The highest both roughtess and wettability were characterised for nanocomposites materials modified by CNT, that is why this nanocomposite seems to be the most suitable for bone cells grown and proliferation.

\section{Conclusion}

Polylactide and polycaprolactone with ceramic or carbon nanofillers are suitable nanocomposites for the growing and proliferation of human osteoblast-like MG63 cells. The presence of nanoceramic fillers facilitates the cell adhesion in shorter time than in case of pure polymers. The highest polulation of cells (compared to polyethylene dishes) was detected on the nanocarbone surfaces. We concluded that carbon nanotubes as well as ceramic particles are effective for growing and proliferation of bone cells. It seems that applied nanocomposites 
espacialy filled with carbon nanotubes might be usefull materials for tissues regeneration process. However for confirmation of this thesis more and deeper studies of the chemical, crystalline as well as biological surface properties are needed.

\section{Acknowledgments}

This work was financially supported by the Polish Ministry of Science and Higher Education, project no N N507 463537

\section{References}

[1] B. Sitharaman, X. Shi, X.F. Walboomers, H. Liao, V. Cuijpers, L.J. Wilson, A.G. Mikos, J.A. Jansen, Bone 43, 362 (2008).

[2] J.T. Feng, J.W. Sui, W. Cai, J.Q.. Wan, A.N. Chakoli, Z.Y. Gao, Mater. Sci. Eng. B 150, 208 (2008).

[3] J. Feng, W. Yan, Z. Gou, W. Weng, D. Yang, J. Mater. Sci., Mater. Med. 18, 2167 (2007).
[4] A. Vallés-Lluch, G. Gallego Ferrer, M. Monleón Pradas, Eur. Polym. J. 46, 910 (2010).

[5] Y. Dong, S.-S. Feng, Biomaterials 26, 6068 (2005).

[6] K. Sahithi, M. Swetha, K. Ramasamy, N. Srinivasan, N. Selvamurugan, Int. J. Biol. Macromol. 46, 281 (2010).

[7] A. Fraczek-Szczypta, E. Stodolak, A. Wiecheć, M. Błażewicz, Eng. Biomater. 13, 1 (2010).

[8] http://www.absoluteastronomy.com/topics/ Tensile_strength

[9] C.M. Sayes, A. M Gobin, K.D. Ausman, J. Mendez, J.L. West, V.L. Colvin, Biomaterials 26, 7587 (2005).

[10] D. Labelle, C. Jumarie, R. Moreau, Cell Prolif. 40, 866 (2007).

[11] L. Bacakova, L. Grausova, J. Vacik, A. Fraczek, S. Błażewicz, A. Kromka, M. Vanecek, V. Svorcik, Diam. Relat. Mater. 16, 2133 (2007).

[12] F. Gentile, L. Tirinato, E. Battista, F. Causa, C. Liberale, E.M. di Fabrizio, P. Decuzzi, Biomaterials 31, 7205 (2010). 